\title{
Forest biotechnology makes its position known
}

\author{
Steven Strauss, Wout Boerjan, John Cairney, Malcolm Campbell, Jeffrey Dean, David Ellis, Lise Jouanin, and Björn Sundberg
}

Last July, the world's largest group of scientists studying molecular biology and biotechnology of forest trees met at the University of Oxford, England ${ }^{\star}$. To the surprise of the attendees, the meeting, organized by the International Union of Forestry Research Organizations (IUFRO, Vienna, Austria), was the subject of a protest by an antibiotechnology group called GEFF (Genetic Engineering Free Forests, London, UK). During the meeting, GEFF staged a protest outside the meeting hall (the venerable Oxford Natural History Museum) that drew about 30 participants. In addition, the only field trial of genetically modified (GM) trees in the United Kingdom, poplars with modified wood chemistry growing on AstraZeneca's property west of London, was destroyed by vandals at the outset of the meeting.

These trees had been generated through a collaborative research project funded by the European Union. The protest and the destruction of the field trial seemed to be sending the message that even research to understand how trees function at the molecular level was unwelcome. This is curious, as a key complaint of groups like GEFF, who are against GM organisms (GMOs), is that the knowledge base to assure environmentally safe use is insufficient. In addition to obtaining wood for analysis of pulp characteristics, seeing whether the genetic modification had any effects on tree growth and adaptation to

Steven Strauss is a professor at Oregon State University, Corvalis, $O R$

(strauss@fsl.orst.edu); Wout Boerjan is a group leader at Flanders Interuniversity, Gent, Belgium (woboe@gengenp.rug.ac.be); John Cairney is an associate professor at the Institute for Paper Science and Technology, Atlanta, GA (john.cairney@ipst.edu); Malcolm Campbell is lecturer at Oxford University, Oxford, UK

(malcolm.campbell@Plant-

Sciences.oxford.ac.uk); Jeffrey Dean is a professor at the University of Georgia, Athens, GA(jeffdean@uga.edu); David Ellis is biotechnology director at $B C$ Research, Vancouver, BC, Canada (dellis@bcresearch.com); Lise Jouanin is a research scientist at INRA, Versailles, France (jouanin@versailles.inra.fr); Björn Sundberg is a professor at the Swedish University of Agricultural Science, Umeå, Sweden (Bjørn.Sundberg@genfys.slu.se). the environment was an important rationale for the study. Its ultimate goal was to produce trees that require the use of fewer chemicals in paper and pulp production, and thus creating less environmental pollution.

During the session on the deployment of GM trees, and at the business meeting, IUFRO scientists debated a draft position statement on the benefits and risks of GM crops and plantations. Based on comments from the group, the statement was revised and put to a vote via the Internet. It was ratified by $99 \%$ of those who voted. The details of the vote, and the full text of the position statement, are available at: http://www.fsl.orst.edu/tgerc/iufro_posstatm.htm. Some of its key points include the following:

In forestry, GM trees are likely to be used primarily in intensive, short-rotation (e.g., 3-25 years) plantations for which wood production is the primary goal. These plantations are effectively tree farms, but can be integrated within landscapes that contain diverse land uses and forest types. Apart from the possible use of transgenic trees to help resurrect wild forest species that have been devastated by an exotic pest, IUFRO attendees do not expect them to be planted in lightly managed woodlands or to become significant components of native forests.

Plantations of genetically engineered trees could help to increase wood production, and thereby reduce pressure for exploitation of native forests. The world's demand for renewable energy, fiber, and building materials from wood is growing rapidly. Plantation area in the developing world doubled from 1980 to 1995, and is expected to double again by 2010 . World fiber production increased roughly $100 \%$ between 1970 and 1994, and per capita consumption increased $50 \%$ in the developed world and $300 \%$ in the developing world (FAO 1997: http://apps.fao.org). Because of population pressure and the imperative that large areas of native forests be set aside from intensive exploitation to preserve their environmental values, research is needed to identify scientifically prudent alternatives, including the use of GM trees, that improve wood quality and yield.

The social discussion about risks $v$ s. benefits of GMOs must move from a generic consideration of GMOs to the merits of modifying trees with specific traits to be used in specific environments and management regimes. Similar to traditional breeding, genetic engineering can produce completely innocuous conse- quences or it can produce substantially modified organisms. The large-scale use of transgenic crops in some countries show that transgenic traits can be highly stable after normal field screening of genotypes during breeding. The credible issues center on which genes can be effectively used to modify which traits for which environments.

While transgenic traits pose some risks for plantations and associated ecosystems, many options exist to mitigate their impacts. Priority research areas include (1) the isolation, modification, and testing of additional genes, and systems for gene regulation, to impart traits without undesired effects on tree development or ecosystem function; (2) studies to support resistance management programs for use of pest-resistant trees; (3) efficient transformation methods so that genetic diversity is not unintentionally impaired as a result of inability to produce large numbers of useful transgenic genotypes; and (4) methods to modify flowering to allow reliable containment of transgenes within plantations when ecologically prudent. Field trials are crucial for all of these research objectives, and can be done with a high degree of environmental safety.

The attendees at the Oxford meeting all seemed to agree that GMOs raise a number of new socioeconomic issues that must be dealt with through discussion and free exchange of information. The high level of technology required, and the costly legal issues associated with patents and government regulations that GMOs bring about, raise new questions for society to grapple with. Some level of public controversy is expected and desirable. The IUFRO Working Party hopes is that their position statement will help to bring sound science to bear on this discussion as it plays out within forestry, and will stimulate further research to ensure that the vast potential for genomic engineering of forest plantations does not go untapped.

*The meeting, called "Forest Biotechnology 99" (http://users.ox.ac.uk/ dops0022/conference/forest_biotech99_home.html), was a joint meeting of the International Union of Forestry Research Organizations (IUFRO:

http://iufro.boku.ac.at/) Working Party on Molecular Biology of Forest Trees (2.04.06) and the International Wood Biotechnology Symposium. The meeting was attended by more than 190 scientists representing 30 different countries, and covered all facets of the use of molecular biology for the breeding and genetic analysis of forest trees. 